\title{
Las víctimas del conflicto armado colombiano en la Ley de Víctimas y Restitución de Tierras: apropiación y resignificación de una categoría jurídica
}

\author{
Mariana Delgado Barón*
}

\author{
Perfiles Latinoamericanos | Artículo \\ vol. 23 | núm. 46 | 2015 \\ pp. $121-145$
}

\begin{abstract}
Resumen
La Ley 1448 de 2011, o Ley de Víctimas y Restitución de Tierras, se implementó en 2012 como un mecanismo jurídico adoptado en medio del conflicto armado interno colombiano para restituir las tierras a los que habían sufrido su despojo por parte de alguno de los actores alzados en armas. Así, esa Ley establece quiénes tienen acceso al derecho a la restitución y a la reparación (simbólica o económica), y de esta forma define un nuevo universo de víctimas, con lo que ha ampliado el debate acerca de la noción de víctima, no solo como una categoría jurídica claramente definida en la Ley, sino como un concepto que caracteriza y delimita a determinados tipos de sujeto. Este artículo contribuye a la discusión que abrió la Ley 1448 acerca de la significación y resignificación de la noción de víctima, y de las dinámicas de subjetivación política que aún se generan en torno a este proceso sociojurídico y político.
\end{abstract}

\begin{abstract}
Law 1448 of 2011, or Victims and Land Restitution's Law, was implemented on 2012 as a juridical mechanism adopted in the middle of the Colombian armed conflict for the land's restitution to those who were deprived of it for some of the armed actors. This law establishes who has access to the right of restitution and reparation (symbolic or economical), and in this way once again it defines a victim's universe. The implementation of this law allow to broaden the debate about the victim's notion not only as a juridical category, clearly delimited and defined in the text of the law, but also as a notion that characterizes and delimited particular kinds of subjects. In this article, the author to contribute to the discussion about the meaning of the victim's notion that the law has produced and about the dynamics of political subjectivation related with this social, political and juridical process.
\end{abstract}

Palabras clave: Ley de Víctimas y Restitución de Tierras, noción de víctima, conflicto armado colombiano.

Keywords: Victims and Land Restitution's Law, victim's definition, Colombian armed conflict.

* Politóloga y maestra en Ciencia Política por la Universidad de Los Andes (Bogotá, Colombia), maestra en Política Internacional por la Universidad de Birmingham (Inglaterra), doctora en Investigación en Ciencias Sociales con mención en Sociología por la Flacso México. Recientemente finalizó una estancia posdoctoral en la Facultad de Ciencias Políticas y Sociales de la UnAm. 


\section{Introducción ${ }^{1}$}

on la Ley de Víctimas y Restitución de Tierras (LVRT), implementada recientemente por el gobierno colombiano, siguió ampliándose el debate acerca de la noción de víctima, no solo como una categoría jurídica claramente definida en esa Ley, sino como término que caracteriza y delimita a determinados tipos de sujeto.

La Ley 1448 de 2011, "por la cual se dictan medidas de atención, asistencia y reparación integral a las víctimas del conflicto armado interno y se dictan otras disposiciones", tiene por objeto

[...] establecer un conjunto de medidas judiciales, administrativas, sociales, económicas, individuales y colectivas en beneficio de las víctimas contempladas en el artículo $3^{\circ}$ de la presente ley, dentro de un marco de justicia transicional, que posibiliten hacer efectivo el goce de sus derechos a la verdad, la justicia y la reparación con garantía de no repetición, de modo que se reconozca su condición de víctimas y se dignifique a través de la materialización de sus derechos constitucionales (Ley 1448, 2011: artículo $1^{\circ}$ ).

Del mismo modo, la LVRT establece la regulación relacionada con la ayuda humanitaria, la asistencia, la atención y la reparación a las víctimas que en ella quedan reconocidas; en tanto que define a las víctimas como "aquellas personas que individual o colectivamente hayan sufrido un daño por hechos ocurridos a partir del $1^{\circ}$ de enero de 1985 , como consecuencia de infracciones al Derecho Internacional Humanitario o de violaciones graves y manifiestas a las normas internacionales de Derechos Humanos ocurridas con ocasión del conflicto armado interno" (Ley 1448, 2011: artículo $3^{\circ}$ ).

La apuesta gubernamental por la LVRT en parte estuvo determinada por el interés del presidente Santos en ser reelegido por cuatro años más. Sin embargo, su aprobación e implementación también obedecen a intereses más generales, originados en la necesidad de finalizar el conflicto armado interno, y por otros que se orientan a abrir el debate sobre la reforma agraria, uno de los puntos álgidos que determina la continuidad o no del conflicto armado, y que están

1 Este artículo se inscribe dentro del proyecto de investigación "Ley de Víctimas y Restitución de Tierras en Colombia: constitución de un espacio social, jurídico y político para las víctimas del conflicto armado", en el marco de las estancias posdoctorales de la Facultad de Ciencias Políticas y Sociales de la Universidad Nacional Autónoma de México financiadas por la Dirección General de Asuntos de Personal Académico (DGAPA). La autora agradece en especial a la doctora Angélica Cuéllar Vázquez por sus comentarios, sugerencias y lectura atenta de las versiones preliminares del documento. 
dados en cierta medida por las actuales negociaciones de paz entre el gobierno colombiano y los representantes de las Fuerzas Armadas Revolucionarias de Colombia (farc). En estas negociaciones se han discutido cinco temas principales: a) la política de desarrollo agrario integral, b) la participación política, c) la finalización del conflicto, d) la solución al problema de drogas ilícitas, y e) las víctimas. ${ }^{2}$

Por otra parte, cabe preguntarse cómo se han apropiado las víctimas de la LVRT o cómo se han posicionado frente a la misma, y cómo han resignificado la definición de víctima que allí se ofrece y la que contiene la Ley 795 de 2005, o Ley de Justicia y Paz. ${ }^{3}$ La LVRT de 2011 refleja una instrumentalización política por parte del gobierno, y otra por parte de las asociaciones de víctimas, las cuales se posicionan de un modo determinado frente a esa legislación, de donde deriva que la ley es lo que de ella se hace, una cuestión que también se define por el tipo de relaciones que resultan de la producción de las normas jurídicas: "las normas jurídicas no poseen vida propia, por tanto no imponen el orden social; la raíz de ellas, la naturaleza de las normas jurídicas y de sus ordenamientos están determinados por las relaciones sociales [...]. La forma jurídica se corresponde con la construcción y organización específica del orden social" (Rodríguez, 2010: 26, 28).

Este artículo es una reflexión acerca de la concepción de las producciones jurídicas como "mecanismos de poder y control social utilizados para la producción y reproducción del sujeto y la subjetividad" (Rodríguez, 2010: 31), que a la vez fungen como resultado de las mismas relaciones y prácticas sociales, particularmente en el marco contextual de la LVRT. Se busca contribuir a la discusión acerca de la significación y resignificación de la noción de víctima que abre la Ley 1448, y de las dinámicas de subjetivación política que aún se generan alrededor de este proceso sociojurídico y político. Para dichos propósitos, el artículo se ha dividido en cuatro apartados: el primero se centra en plantear las preguntas pertinentes sobre la categoría de víctima en términos generales, y en aquellos que se establecen en la LVRT, para así determinar lo problemático de dicha definición, los elementos que delimitan ese universo de víctimas, y las formas — si las hay_ de resignificación o reapropiación de tal categoría. En el

2 Acuerdo general para la terminación del conflicto y la construcción de una paz estable y duradera (2012), [en línea], disponible en <http://www.indepaz.org.co/wp-content/uploads/2012/09/Acuerdo-generalpara-la-terminación-del-conflicto-y-la-construcción-de-una-paz-estable-y-duradera1.pdf`, consulta del 10 de septiembre de 2012.

3 La Ley de Justicia y Paz fue aprobada durante el primer mandato del presidente Álvaro Uribe Vélez con el fin de constituir un marco jurídico para el desarme, la desmovilización y la reinserción de los grupos armados al margen de la ley, particularmente de las Autodefensas Unidas de Colombia (AUC), una confederación de grupos paramilitares. 
segundo apartado se plantea una relación entre la apropiación y resignificación de la categoría, con los procesos de subjetivación política que se han visibilizado y han tomado más fuerza desde el proceso de justicia y paz iniciado en 2005 con la implementación de la Ley 975, allí se señala la coexistencia de dos momentos en el orden social: el de la sujeción, y el de la subjetivación. En el tercer apartado se introduce la reflexión acerca de la apropiación de la ley por parte de las víctimas, lo que pone de manifiesto dos aspectos: a) que la producción de la demanda y la expresión de la voluntad colectiva (para el caso de las asociaciones de víctimas) son instancias que en algunos casos anteceden a la constitución del sujeto, y, en otros, son indispensables y fundamentales para la misma, y b) que la promulgación de la Ley 1448 determina ese proceso constitutivo; en otras palabras, la LVRT, así como la Ley de Justicia y Paz, son instancias previas (a pesar de sí mismas) que determinan la constitución de la víctima como sujeto histórico, político y colectivo, porque les permite situarse de una forma en particular frente a una interpretación jurídica, lo que abre paso a la lectura de un proceso sociopolítico, como el conflicto armado colombiano. Esto sin desconocer las fuertes críticas y cuestionamientos en materias de verdad, justicia y reparación que provienen de las mismas asociaciones de víctimas y organizaciones defensoras de los derechos humanos, y sin pretender desconocer tampoco los procesos de subjetivación política que anteceden a estas leyes. En este apartado se reproducen algunos comunicados provenientes de asociaciones de víctimas y organizaciones defensoras de derechos humanos que dan cuenta de dicho posicionamiento. Por último, se resumen las principales consideraciones finales relativas a los temas tratados.

\section{¿Qué delimita la categoría de víctima?}

La víctima puede ser asociada a diversos conceptos: con el "ocupante sin lugar" en los procesos de justicia transicional, con la figura de "testigo" —y en este sentido, con una parte más activa en los procesos penales-, como "sobreviviente", e incluso como sujeto de "orgullo y dignidad" (Guerrero, 2007; Booth, 2007; Wieviorka, 2009, citados por Delgado, 2011:37-38). En relación con esta última acepción, recientemente se habla de las víctimas como "sujetos de justicia", "testigos históricos de excepción", "portadores de memoria” y portadores de una "superioridad moral" en relación con sus victimarios (Villa et al., 2007; Cepeda, 2006, citados por Delgado, 2011: 40).

Estas últimas referencias se relacionan con una noción de víctima que parte del autorreconocimiento de estas como sujetos a partir principalmente de procesos de recuperación de las memorias no oficiales que, en el caso colombiano, 
se circunscriben al conflicto armado. En otras palabras, las mismas víctimas reclaman un nuevo reconocimiento que las distancie de la concepción de sujetos pasivos y las sitúe como sujetos políticos que asumen una ciudadanía diferente (Carrizosa, 2011).

De esta forma, la lucha por el reconocimiento como sujetos políticos se vincula a la concepción de la memoria como construcción política, puesto que posibilita la visibilidad de una o de varias historias como formas alternativas de representación, en las que se da "un proceso que dota a una experiencia de sentido y significado", a un "proceso intersubjetivo de diálogo entre los individuos y la sociedad" (Carrizosa, 2011).

Igualmente, la recuperación de estas memorias no oficiales, inscritas en el conflicto armado colombiano, son "memorias de un sufrimiento que es narrado, agenciado y representado por los dolientes", cuya naturaleza es reparadora y movilizadora del duelo; asimismo, la recuperación de la memoria constituye un esfuerzo colectivo que no solo se encamina a relacionar pasado, presente y futuro, sino también a víctimas, hechos y responsables (CNRR, 2009). La recuperación de una memoria de la violencia narrada por las víctimas del conflicto da cabida a su fortalecimiento social y político (CNRR, 2009). Respecto a esto último, esa reconstrucción de la memoria que proviene de las víctimas y de los dolientes implica diferentes procesos de resistencia simbólica, y de resignificación de historias y del pasado, lo que conlleva a la resignificación de los sujetos, de los objetos y de los mismos territorios atravesados por el conflicto armado (CNRR, 2009).

Esta resignificación y dignificación de las víctimas y de su pasado se enmarca en la construcción de una memoria reivindicativa que pone de manifiesto el dolor y el sufrimiento en la escena pública, y se inscribe en la búsqueda del "reconocimiento de la gravedad moral del acontecimiento" (Blair, 2008: 246, citada por Carrizosa, 2011). En esta misma dirección, el impacto de una memoria reivindicativa como una lucha política se asocia no exclusivamente con su traducción inmediata en política pública, sino principalmente con las formas en que afecta o incide en la experiencia subjetiva de las víctimas que participan en las diferentes "modalidades" de resistencia y de visibilización (Blair, 2008, citada por Carrizosa, 2011).

La lucha por el reconocimiento de las víctimas también se expande al terreno del significado de la noción de víctima. Así, el debate se ha construido alrededor de la pregunta acerca de las formas en que las víctimas se nombran a sí mismas, sin olvidar la carga simbólica y política de la categoría. En esta adquisición de nuevos y diferentes sentidos, se produce una apropiación social de la noción, y si bien en la ley la noción de víctima se limita a una categoría jurídica, en los procesos mencionados se evidencia la naturaleza emocional que encierra (Jimeno, 2010): "la importancia de la categoría de víctima radica en la posibilidad 
de expresar los hechos de violencia desde quienes la han sufrido, articulando en esta narrativa las emociones con la acción política" (Jimeno, 2010, citada por Carrizosa, 2011: 54).

Lo anterior descubre la importancia inicial del acto de nombrar: es un punto de partida; la categoría de víctima se constituye en el paso a la acción y la participación en procesos sociales y políticos (Carrizosa, 2011). Asimismo, este acto de nombrar y de clasificar jurídicamente es clave en los procesos de subjetivación política que también parten, se alimentan y se configuran con las apropiaciones y resignificaciones de la noción de víctima. A propósito, la lucha por el reconocimiento y resignificación de la noción de víctima se enmarca en la discusión propuesta acerca de dicha noción como una "condición" casi inmutable, que está dada de una vez y para siempre, a fin de situarla en el terreno de una "situación" transitoria: "puede pensarse en ser víctima no como una condición, sino como una situación, un estado transitorio que no se olvida pero que debe ser punto de partida para otras construcciones de los sujetos" (Carrizosa, 2011: 54). Al respecto, Blair (2008) afirma que "las víctimas no sólo son víctimas de acciones, actores y hechos en situaciones y momentos específicos, sino que también y pese a su sufrimiento, su vida no se desarrolla sólo en esa dirección"; esto implica pasar de la noción de víctima como una condición a la noción de víctima ligada a una situación, de esta forma es posible concebir a las víctimas como sujetos activos capaces de generar acciones transformativas, que se "apropian de una vivencia de violencia y la transforman en un motor para la acción y para la movilización” (Delgado, 2011: 46).

En relación con estas ideas, nombrar a las víctimas y definirlas en tanto categoría clarifica un momento histórico en particular; el acto de nombrar es también reflejo de los procesos sociales, políticos y judiciales de la época, que en este caso se encuentra sujeto a los procesos de justicia y paz y a la LVRT, "las denominaciones también dependen del escenario en el cual se producen [...], el acto de nombrar pone en escena [...] visiones de procesos y valoraciones antagónicas de acontecimientos históricos" (Sánchez, 2006, citado por Delgado, 2011: 45).

Pasar de considerar a las víctimas como sujetos pasivos y anclados a una condición permanente, para aproximarnos a la categoría partiendo de su transitoriedad, por la cual se establece que estos sujetos se encuentran en una situación que puede cambiar, es reconocer las posibilidades de su acción y movilización, y también de la expresión de su subjetividad.

Quedarse en el terreno de la víctima como condición, es caer en la revictimización y reducir u obstruir su espectro de acción; por otra parte, reconocer en las víctimas una capacidad de agencia es identificar que su situación no define exclusivamente su esencia y que, por el contrario, las víctimas pueden transformar la situación, "pasar de la condición de víctima a la situación de víctima impide 
en cierta forma y grado que se generen dinámicas de revictimización que generalmente se encuentran permeadas por el carácter temporal de la permanencia, que a su vez están cargadas de sospechas de culpabilidad" (Blair, 2008, citada por Delgado, 2011: 46).

Si bien se reconoce el carácter transitorio asociado a la noción de víctima, en un primer momento esta situación se encuentra directamente vinculada con la pérdida y el daño provocado. Wieviorka (citado por Blair, 2008) confirma que el ser víctima se define a partir de la pérdida, lo cual no se reduce a la "pérdida de vidas humanas sacrificadas en la guerra”, sino a otra que abarca términos más amplios y que se expresa en "otras esferas de la vida social, produciendo una sumatoria de pérdidas, que exige para las víctimas, verdades, justicias y reparaciones más integrales" (Blair, 2008: 243a). Wieviorka enfatiza, asimismo, en el tipo de emociones generadas por las pérdidas que sufren las víctimas; esas no se definen en exclusiva por las emociones negativas del sufrimiento, sino que, por el contrario, "parecen corresponder no sólo a la mitad del sujeto, sino a la parte de sombra de su identidad" (Wieviorka, citado por Blair, 2008: 12). En otras palabras, "se reconoce que la pérdida es un factor constitutivo de la víctima, pero que define sólo una parte de su identidad, y que al ser reapropiada y dotada de nuevos significados por la víctima, se concibe como un elemento generador de acción” (Delgado, 2011: 47).

La víctima, entonces, se constituye como sujeto a partir de lo que decide hacer con la experiencia negativa, con el sufrimiento padecido, y con la forma en que enfrenta - y por qué no- supera la situación de violencia a la que ha sido sometida: "esta constitución de las víctimas como sujetos debe partir de una noción o significado de la figura de la víctima más inclusiva en cuanto a que ésta no es meramente una figura asociada a la decadencia, sino que por el contrario, acorde con Wieviorka, la víctima emerge como sujeto cuando la sociedad reconoce el sufrimiento que ha padecido y el impacto que éste ha generado en su vida" (Wieviorka, 2009, citado por Delgado, 2011: 47). En este sentido, parte del proceso de subjetivación política de las víctimas se origina en la necesidad de dotar a la noción de víctima de nuevos significados.

Si la figura de la víctima se asocia en un primer momento a la pérdida y el daño, también puede incorporar las nociones de sacrificio y de condena (Ravinovich, 2003, citada por Acevedo, 2012). Por otra parte, la figura de la víctima "encarna a los dominados y excluidos" del sistema y pone de manifiesto que no solo "no se ha reconocido jurídicamente la figura de crimen de Estado", sino que, en esa búsqueda, las víctimas luchan además por el reconocimiento de una situación histórica, que coloca en la escena política y social el conflicto que se da los victimarios, el Estado y las víctimas sobre "las interpretaciones, representaciones y significaciones del pasado" (Acevedo, 2012). 
Sobre la concepción de las víctimas como excluidos, Dussel especifica que "bajo el amparo del Estado de derecho las víctimas son resumidas en los sin derecho del sistema", e incluso "son las mismas víctimas de dicho sistema quienes conociendo su situación incorporan nuevos derechos en un doble proceso, de deslegitimación del antiguo derecho (legal) y legalización del nuevo derecho (legítimo)" (Dussel, citado por Acevedo, 2012: 5). Esta "conciencia de ser un sujeto sin derechos" es la que incentiva la subjetivación política que se inscribe en de la noción de víctima como sujeto de memoria y, sobre todo, como sujeto histórico.

Es importante enfatizar que en la constante configuración del orden social ocurre también la de sujetos políticos y sociales "que disputan por los ordenamientos históricos", porque este orden social es una "construcción hegemónica" en la que se reproducen desigualdades y lugares dominantes y subalternos (Retamozo, 2010: 83). Las víctimas se ubican en estos últimos.

La relevancia que ha comenzado a cobrar desde hace pocos años la perspectiva de las víctimas en Colombia, refleja la importancia y visibilidad que han adquirido los procesos de subjetivación de las víctimas y la coexistencia de "diferentes memorias", de diferentes "relatos acerca del conflicto político, social y armado" (Acevedo, 2012: 2).

Esta configuración produce desigualdades en el orden social y deja un espacio para la resistencia y la disrupción, aunque "esto no significa que en estos nodos se erijan necesariamente la rebelión o la lucha social como respuestas [...] el conflicto social, así como el sometimiento, es un proceso histórico, social, contingente" (Retamozo, 2010: 84). Podemos identificar que en el orden social en donde se reproducen relaciones de poder, de dominación y por ende de subordinación, hay espacio para la resistencia y la subversión de esas relaciones de poder, es así como ese espacio es también de la subjetividad de los actores, tal como lo señalara Foucault (citado por García, 2006). En este orden de ideas, "el ejercicio del poder no se despliega sobre la pasividad de los sujetos, no sólo porque donde hay poder hay libertad, sino también porque esas relaciones sociales de subordinación pueden ser lugares de resistencia colectiva" (Retamozo, 2010: 84). Claro está, el espacio de la resistencia no conduce inmediata o necesariamente a la rebelión, sino que forma parte de un proceso social en el que "los sujetos deben ser vistos, en su proceso de constitución, como condensadores de historicidad" (Zemelman, 1990, citado por Retamozo, 2010).

En este proceso de configuración de la subjetividad, el componente colectivo es fundamental para la elaboración de las demandas y para la construcción de identidad; el sujeto como "construcción histórico-política" se configura a partir de la experiencia colectiva, que da lugar a la elaboración de demandas y a la apropiación y construcción de la historia (Retamozo, 2010: 85), y en tal 
sentido, "instancias como la producción de la demanda, la decisión y la voluntad colectiva son analíticamente previas a la constitución del sujeto" (Retamozo, 2010: 85).

Esta idea de la subjetividad colectiva adquiere un nuevo significado cuando partimos de una concepción del orden social como el espacio en el que se producen y distribuyen posiciones de sujeto (Retamozo, 2010: 85), puesto que esta subjetividad colectiva entra a jugar un papel determinante y fundamental al momento de otorgar nuevos sentidos a la noción de víctima, y más ampliamente, al disputar los "sentidos dominantes", en este caso, acerca de la verdad, la justicia, la reparación, la memoria y la reconciliación, entre los diversos que imperan en el orden social y que determinan el lugar de víctimas y victimarios en él, es decir, "allí convergen tanto el momento de sujeción (producido por el orden) como el de subjetivación capaz de generar nuevos lugares de enunciación y acción histórica" (Retamozo, 2010: 85). La configuración de una subjetividad colectiva busca "dotar de sentido a las situaciones compartidas", y esto implica la reconstrucción de una o varias memorias como parte del proceso de resignificar y reconstruir el pasado y sus diferentes sentidos (Sánchez, 2010: 132).

El orden social, y más particularmente el campo social del que habla Bourdieu, es un espacio en el que los agentes se encuentran posicionados en un determinado lugar que pueden modificar si se les da los recursos y estrategias de juego que posibiliten el reposicionamiento, lo que puede condicionar una reconfiguración de ese mismo campo. Considerando esto, y dadas las dimensiones activa y pasiva de la subjetividad que pueden converger en este espacio, si bien "el resultado es la reapropiación de la situación posicional desde otros parámetros a partir de la incorporación de diferentes elementos en el proceso subjetivo [...] estos elementos no son por necesidad emancipatorios" (Retamozo, 2010: 85). No obstante, tal reapropiación de la situación posicional y de la reconfiguración del espacio social y de la subjetividad, son procesos que derivan en antagonismos sociales, en la estructuración de un nosotros y un ellos-otros; ese nosotros corresponde a una colectividad que se define en relación con un daño que "conlleva la formación — aunque inicialmente difusa — de una identidad que demanda a otro en referencia a ciertos aspectos puntuales" (Retamozo, 2010: 86), y que, en el caso de las víctimas del conflicto armado colombiano, dicho daño las ha afectado en sus derechos a la verdad, la justicia, la reparación y las garantías de no repetición.

Las víctimas encarnan el sujeto que reclama por el daño, por la pérdida y por una reconfiguración del orden social que las niega, y las relega a la invisibilidad y a la subalternidad. El reconocimiento de las víctimas en un espacio común de subalternidad les permite construir una subjetividad colectiva que "signifique el daño en términos políticos", que les permita reconocerse como 
una "comunidad con conciencia explícita de encontrarse en una situación de

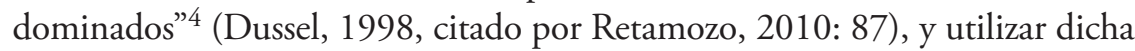
conciencia para organizarse y movilizarse.

Podríamos establecer un vínculo entre esta posición de subalternidad que acompaña a las víctimas dentro del ordenamiento social con la forma pasiva con la que se las asocia en el régimen penal, en donde, como "sujeto pasivo de infracción", solo le corresponde "la denuncia del daño sufrido", por lo que, en consecuencia, existe un momento previo al reconocimiento de la víctima como sujeto de derechos, el cual consiste en la relación entre derecho y violencia, mismo que "pasa por la formalización de la víctima como sujeto cuyo derecho es la asistencia", ${ }^{5}$ lo que da como resultado a una víctima que se concibe como el sujeto desvalido y situado en un lugar de asistencia. La víctima es así reconocida como "sujeto fragilizado, carente, sufriente, cuyo derecho es un servicio, una prestación, una gestión" (Daza, 2006: 112-114). Bajo esta concepción, a la víctima se le naturaliza como inocente y adicionalmente es objetivada por las acciones de carácter humanitario que solo consiguen abstraerla de la política "pues la víctima así definida, es mostrada, pensada y aprehendida como ser sufriente y vulnerado, mientras que la violencia se hace casi innombrable e inaprensible en sus causas" (Daza, 2006: 116).

\section{Las dinámicas de la subjetivación política: ¿qué tipos de sujetos son las víctimas?}

En los párrafos anteriores se mencionaron algunas de las resignificaciones que ha adquirido la noción de víctima, una de las cuales establece la figura del daño,

4 Cabe aclarar que esta situación no caracteriza a todas las víctimas. En otras palabras, hay víctimas pobres, otras que no lo son, y las hay que no se encuentran "dominadas" (aunque, en el caso colombiano, en su mayoría se perpetúen estas lógicas de dominación).

De la misma forma, hay individuos que no han sido víctimas y aun así se encuentran en una situación precaria de dominación. Este punto abre un debate importante y pertinente sobre los alcances de las medidas transicionales y, en particular, sobre la justicia correctiva en sociedades que han atravesado conflictos armados. Mientras que la justicia correctiva se dirige a establecer una reparación a aquellos individuos que han sido víctimas de un daño orientándose así a "restaurar el statu quo ante bellum", la justicia social entendida como un "conjunto de principios que permiten identificar algunas distribuciones de bienes y oportunidades en la sociedad como preferibles o superiores a otras", se encamina hacia la igualdad de oportunidades. La justicia social adquiere de este modo una mayor relevancia porque implementa "políticas de redistribución orientadas a garantizar derechos básicos de toda la población" y no solo a "devolver a la víctima de un daño al lugar en el que estaba antes de sufrir tal daño y no simplemente mejorar su situación”, como principio básico de la justicia correctiva. Para un mayor análisis, recomiendo a Pablo Kalmanovitz (2010). (Agradezco a Mauricio Uribe López su valioso comentario al respecto.)

5 Pero más que a la asistencia, el derecho de la víctima es la "reparación" por un dańo sufrido, y bajo este principio, se justifica el "derecho a ser reparado y la obligación de reparar" (Kalmanovitz, 2010: 64). 
de donde se concluye que la víctima lo es porque ha sufrido un daño. Pues bien, no hay que perder de vista que "la percepción de los dañados es subjetiva, y la aproximación a su reconocimiento debe [...] entender los significados subjetivos que las víctimas han atribuido a lo perdido durante la guerra" (Rebolledo, y Rondón, 2010: 42). Y que si la percepción del daño es subjetiva, no se puede desconocer que la repercusión del daño se extiende a la esfera colectiva, de tal modo que es fundamental reconocer este aspecto que afecta a comunidades y a grupos, considerados como "víctimas colectivas" y, por ello, como sujetos de reparación, aunque "los sujetos titulares de la reparación colectiva deben caracterizarse por una identidad colectiva compartida" (Rebolledo, y Rondón, 2010: 44).

En la relación de la víctima con el daño y con la pérdida, vale recordar que, dentro del proceso de reparación a las víctimas, debe reconocerse que estas, frente a la pérdida, vivencian una diversidad de experiencias, y de expectativas, y de los mismos modos de procesar el trauma y el daño, lo que obliga a reconocer "la pluralidad de subjetividades frente a la memoria" (Sánchez, 2008: 4), pero también frente a la acción, la movilización, e incluso frente al olvido. Del mismo modo, la expresión de la subjetividad de las víctimas se encuentra estrechamente ligada al acto de testimoniar o narrar lo ocurrido, aunque el testimonio, en tanto "espacio o formación discursiva”, se determina por "la propia situación histórica de su enunciado y por la posición que el sujeto asume en la sociedad" (Achugar, citado por Blair, 2008: 88). Se reconoce así el potencial político del testimonio, sobre todo cuando su presencia en la esfera pública se constituye en "un espacio compartido, donde se intenta construir o buscar una identidad nueva" (Blair, 2008: 88) con la que se pretende fundar un nuevo sujeto.

Encontramos entonces que, en el caso colombiano, el reconocimiento de las víctimas como sujetos portadores de derechos ha estado acompañado de diferentes procesos de subjetivación política y social que involucran, en mayor o menor medida, el componente de recuperación de la memoria no oficial, en donde el testimonio ocupa un lugar central. Este papel del testimonio puede tomar dos formas: "la función ejemplarizante o la denuncia y la autorización letrada de circunstancias, vidas y hechos que no son patrimonio de la historia oficial o que han sido ignorados por la historia y la tradición vigente y hegemónica en tiempos anteriores" (Achugar, citado por Blair, 2008: 89). Igualmente, el acto de testimoniar remite a la imperante necesidad de las víctimas de ser escuchadas, de alzar su voz para demandar la atención del otro y "denuncia[r] los excesos del poder, [...] la marginación, y [...] el silencio oficial" (Achugar, citado por Blair, 2008: 89). Aún más, el testimonio reconstruye la palabra y los hechos, permite contar la otra verdad y las otras historias, y posibilita el reconocimiento del otro; de ahí su fuerza política (Blair; 2008: 90). 
¿Por qué es importante enfatizar en el testimonio como una de las experiencias subjetivas de las víctimas? Porque permite una combinación "de diferentes modalidades de expresión de la subjetividad y de diferentes estrategias de enunciación" (Blair, 2008: 91). Asimismo, su carácter único lo constituye en "uno de los actos más personales que se puedan realizar, ya que ser testigo es ocupar una topografía única, un lugar que no puede ser reemplazado ni reproducido" (Feldman, citado por Blair, 2008: 91). En esta unicidad y particularidad del testimonio sobresalen "las miradas sobre el pasado", mismas que permiten que las víctimas del conflicto se posicionen social y políticamente, puesto que esas narraciones se constituyen en "reflexiones sobre el propio lugar de cada uno en el mundo" (Jelin, citada por Blair, 2008: 91). Esto resalta de nuevo el componente eminentemente político del testimonio y la posibilidad de brindar la palabra, mediante el acto de narrar, a las víctimas. En otras palabras, el potencial político del testimonio radica en que da la palabra a los que no la han tenido y han sido excluidos; dar la palabra a las víctimas implica escucharlas "desde su dolor y su sufrimiento, y al hacerlo despoja también a las memorias de la violencia de uno de sus principales componentes, el de la subjetividad" (Blair, 2008: 96).

Los testimonios se encuentran ligados a la expresión de la subjetividad, ya que deben ser considerados como "construcciones sociales con base en la subjetividad" (Blair, 2008: 96). En el acto de narrar, de testimoniar, se va construyendo una imagen de un sujeto que ha empezado a resignificar el pasado para así posicionarse de maneras diferentes en la sociedad; en este punto es importante de nuevo resaltar el vínculo entre la memoria y los procesos de configuración de la subjetividad, puesto que la primera, al ser un "recurso de reinterpretación de la realidad", es un recurso y un escenario para que los sujetos encuentren su lugar en el orden social y se posicionen en el mismo (Blair, 2002: 24).

Dada esta relación entre memoria y subjetividad podemos señalar que en Colombia, y debido a las dinámicas del conflicto armado, se encuentran diferentes expresiones de la subjetividad a partir de diversos repertorios de memorias que se extienden a lo largo y ancho del territorio. Es así como estos repertorios de memoria se agrupan no solo en torno a la tierra o, más específicamente, en torno a la recuperación del territorio, sino que se agrupan alrededor de la historia del despojo, del exilio, de la denuncia, o alrededor de memorias que buscan enaltecer y resaltar las identidades ocultas o invisibilizadas por el conflicto, y aquellas que se enfocan a considerar al cuerpo como expresión privilegiada de la subjetividad (CNRR, 2009).

Otra importante concepción de las víctimas del conflicto armado colombiano sugiere concebirlas como plenos ciudadanos con derechos, especialmente a las víctimas organizadas y movilizadas que han logrado ir configurando proyectos colectivos de reconstrucción de sus comunidades y regiones, como 
el Oriente Antioqueño, ${ }^{6}$ en donde coexisten varias voces, narrativas e historias que permiten la producción de sujetos políticos y otras formas de pensar nuevas relaciones con la institucionalidad; estas víctimas "se proponen dejar su condición de desubjetivación por la violencia y de entes pasivos para asumir su posición de ciudadanos con derechos" (García, 2009: 91).

En esta misma dirección, organizaciones de víctimas como la Ruta Pacífica de las Mujeres ${ }^{7}$ y la Iniciativa Mujeres Colombianas por la Paz-Imp, ${ }^{8}$ señalan la importancia de los desarrollos jurídicos en relación con la búsqueda de la verdad, la justicia y reparación de las mujeres víctimas del conflicto, para la construcción de una ciudadanía alternativa en donde la mujer se ha constituido en actor social clave con capacidad de negociación a través de "la politización del dolor y del sufrimiento [...] y de la apropiación del espacio público para la deliberación" (Ibarra, 2011: 270), como lo vienen haciendo las Madres de la Candelaria 9 en la ciudad de Medellín, Antioquia.

Esta politización de las víctimas permite cuestionar e incluso buscar el reemplazo de la noción de víctima "que no es sólo un descriptor en el plano jurídico, sino un contenido del discurso cotidiano compartido por diversos actores que en su uso la han transformado en una comprensión que, en ocasiones supone marginalidad, incapacidad, dependencia e incluso peligrosidad" (Valencia, 2010: 66).

6 El Oriente antioqueño ha sido, junto con otras regiones de Colombia, una de las zonas en las que el conflicto armado ha alcanzado su máxima expresión a través del desplazamiento forzado, las extorsiones, la expansión del paramilitarismo y la presencia guerrillera, entre otros.

7 La Ruta Pacífica de las Mujeres "es un movimiento feminista que trabaja por la tramitación negociada del conflicto armado en Colombia, por la visibilización de los efectos de la guerra en la vida de las mujeres y por la exigibilidad de los derechos a la Verdad, la Justicia, la Reparación y la reconstrucción de la memoria histórica individual y colectiva para la No Repetición”. Forma parte activa del Movimiento Ciudadano por la Paz y está constituido por alrededor de trescientas organizaciones y grupos de mujeres en varios departamentos de Colombia. Para conocer mejor el movimiento, se puede consultar el sitio <http://www.rutapacifica.org.co/ruta-pacifica>.

8 IMP "surge en el marco de la resolución 1325 de las Naciones Unidas, aprobada el 31 de octubre de 2000 por el Consejo de Seguridad, insta a los Estados Miembros, actores de conflictos armados, y a personas responsables de planes o procesos de negociación, a atender las especiales necesidades de las mujeres, garantizar protección de derechos, prevención de efectos e incrementar la participación de las mujeres en todos los niveles de decisión, prevención, manejo y resolución de conflictos". Hacen parte de esta iniciativa 22 organizaciones de mujeres que tienen por objeto "lograr la participación activa, decisoria y autónoma de las mujeres, en los procesos de diálogo y negociación política del conflicto armado con todos los actores y aportar en la construcción de procesos de paz", [en línea] disponible en <http://www. mujeresporlapaz.org/index.php?option=com_content\&task=view\&id=3\&Itemid=7>, consultado el 10 de mayo de 2013.

9 Las Madres de la Candelaria realiza un proceso de acompañamiento psicosocial a familiares de víctimas y, más ampliamente, sus actividades se dirigen a "agrupar a los familiares de víctimas de desapariciones forzadas, sensibilizar a la sociedad sobre la problemática de la desaparición forzada, lograr el regreso de los desaparecidos y defender los derechos humanos” (Delgado, 2011: 177). 
Este cuestionamiento a la noción tradicional de víctima que la relega a un lugar pasivo y casi de indefensión, no deja de lado la figura del daño como elemento constitutivo de estos sujetos y de las consecuencias materiales, físicas, morales que el mismo produce; por el contrario, al proponer una concepción diferente se busca superar la aplicación generalizada de una categoría que se imponen por igual a "todas las condiciones vitales de quienes han sufrido un daño", con lo que se pretende prestar atención a la figura del daño y a las condiciones hacia las que la reparación debe focalizarse (Valencia, 2010: 66).

Es así como una reconceptualización de la noción de víctima es fundamental para cambiar la concepción que se tiene de ella, y, en términos más amplios, dicha resignificación se dirige a generar una concepción distinta del conflicto y de otros actores en él involucrados, así como el papel que les ha sido asignado.

En relación con esta reconceptualización y resignificación de la noción de víctima, es pertinente señalar, como lo plantea Rancière, que el proceso de subjetivación política es un "proceso de desidentificación o de desclasificación", cuya lógica obedece a una heterología; es la lógica del otro la que opera según dinámicas de alteridad, en donde la subjetivación "nunca es la afirmación simple de una identidad, sino que siempre es a la vez una negación de una identidad impuesta por otro" (Rancière, 2006: 23).

Esta desclasificación revela el sentido de la política como un "proceso de delimitación en que los hombres, regulando sus divisiones, se constituyen como sujetos" (Lechner, 1986: 20). Asimismo, la lógica de alteridad hace que el proceso de subjetivación se constituya en una lucha por el reconocimiento del otro, en el que los sujetos se constituyen recíprocamente (Delgado, 2011).

En el proceso de subjetivación está en juego, además del reconocimiento por el otro, la posibilidad de que los sujetos tomen las riendas de su vida, de su existencia, y de que asuman el "carácter creativo" en el día a día y en todas sus acciones (Wieviorka, citado por Delgado, 2011). Desde este enfoque, las posibilidades de constituirse en sujeto están dadas por la agencia, por la capacidad de decidir y de actuar, por la capacidad de resistir al poder dominante y de "convertirse en dueños de su propia existencia y de producir sus propias trayectorias" (Wieviorka, 2009: 146).

Tenemos así que esta capacidad de resistencia frente al poder dominante, como característica propia de los procesos de subjetivación, abre las puertas a la producción de movimiento y creatividad que se manifiesta en el ámbito de lo público a través de la expresión del descontento, de la formulación de demandas y otras acciones públicas por parte de los dominados, de los invisibilizados y de los reprimidos. Para el caso de las víctimas del conflicto armado colombiano, estas manifestaciones públicas del descontento son a su vez claros indicios de que la resistencia no necesariamente es anónima y clandestina, y que no se cir- 
cunscribe a los límites trazados por la infrapolítica (para emplear el término de Scott), sino que, por el contrario, la traspasa para hacernos ver que "el reverso de una humillación pública para ser plenamente saboreado necesita también ser público" y, aún más, "la declaración pública del discurso de resistencia puede llegar a desarrollar la capacidad de generar conquistas políticas" (Scott, citado por Delgado, 2011: 58).

Cabe señalar que la capacidad de resistencia referida en los últimos párrafos da la oportunidad a los sujetos de escoger y definir "nuevos modos de existencia" que no necesariamente son inmutables, sino más bien cambiantes y contingentes (García, citado por Delgado, 2011).

Lo anterior permite apuntar una cuestión acerca de las construcciones jurídicas: estas crean formas de sujeción, de dominación de un poder establecido, de control; pero también posibilitan nuevas formas de subjetivación; es decir, la ley impone, es cierto, pero hay un espacio para disponer de ella, para instrumentalizarla, para dotar de otros sentidos y significados a las categorías jurídicas que en ella se definen. Al amparo de estas ideas, es factible afirmar que la ley sí puede constituirse en un punto de partida para procesos de subjetivación política, aunque, para el caso de las víctimas del conflicto armado colombiano, no se pretende desconocer los procesos que han antecedido a la Ley de Justicia y Paz, ni tampoco a la reciente Ley de Víctimas y de Restitución de Tierras. Aun así, se busca resaltar la importancia que, para estos procesos en marcha - y los nuevos que han surgido-, tiene el acto de nombrar (en este caso, el acto de nombrar jurídicamente). Es así como la clasificación y definición jurídica que se hace de las víctimas en la Ley de Justicia y Paz y en la LVRT abrió el debate y el espacio para que las víctimas - y la sociedad en general— comenzaran a resignificar y dotar de nuevos contenidos a esta noción.

\section{Ley de Víctimas y Restitución de Tierras, o lo que se hace de la ley}

La Ley 1448 de 2011 establece que serán consideradas como víctimas "aquellas personas que individual o colectivamente hayan sufrido un daño por hechos ocurridos a partir del $1^{\circ}$ de enero de 1985 , como consecuencia de infracciones al Derecho Internacional Humanitario o de violaciones graves y manifiestas a las normas internacionales de los Derechos Humanos ocurridas con ocasión del conflicto armado interno", ${ }^{10}$ haciendo la salvedad de que "la condición de víctima se adquiere con independencia de que se individualice, aprehenda,

10 “También son víctimas el cónyuge, compañero o compañera permanente, parejas del mismo sexo y familiar en primer grado de consanguinidad, primero civil de la víctima directa cuando a ésta se le hubie- 
procese o condene al autor de la conducta punible y de la relación familiar que pueda existir entre el autor y la víctima” (Ley 1448, 2011: artículo 3º). Del mismo modo, en esa misma Ley son contemplados como víctimas los miembros de la fuerza pública, bajo los términos señalados, y los miembros de los grupos ilegales alzados en armas que hayan sido desvinculado de los mismos siendo aún menores de edad (Ley 1448, 2011: artículo $3^{\circ}$, parágrafo 2).

Esta definición de víctima de la Ley 1448 presenta serios obstáculos para el reconocimiento de las víctimas del conflicto armado colombiano. Por una parte, el universo de víctimas que allí se define es limitado, ${ }^{11}$ pues restringe el reconocimiento de los derechos a las víctimas de crímenes cometidos antes del 1 de enero de 1985, y restringe el acceso a la reparación de tierras a aquellas víctimas que sufrieron del despojo como consecuencia del conflicto armado interno entre el 1 de enero de 1991 y el término de vigencia de esta Ley. ${ }^{12}$

Del mismo modo, las víctimas del paramilitarismo, como fenómeno político, social y económico en curso, son identificadas por el gobierno como "víctimas de delincuencia común organizada o bandas criminales [las bacrim]", y no se encuentran amparadas en la Ley 1448, por lo tanto, no pueden acceder a ninguno de los beneficios que en ella se estipulan. Este hecho sigue generando una jerarquía dentro del universo de víctimas del conflicto armado colombiano que, para el caso de la LVRT, se encuentra definida por la fecha en la que se cometió la violación de los derechos humanos, hecho que determina el tipo de reparación a la que se tiene derecho — simbólica, económica o de restitución de tierras (AI, 2012: 6).

ra dado muerte o estuviere desaparecida. A falta de éstas lo serán los que se encuentren en el segundo grado de consanguinidad ascendente.

De la misma forma se consideran víctimas las personas que hayan sufrido un daño al intervenir para asistir a la víctima en peligro o para prevenir la victimización”, (Ley 1448, 2011: artículo 3º).

Por mencionar un caso, no se reconoce a las víctimas de la delincuencia común, por ejemplo, las víctimas de las bandas criminales emergentes (bacrim), ya que la ley no da cuenta que estas últimas son el rearme y la reorganización de grupos paramilitares. La definición de víctima dada en esta Ley viola así el derecho a la igualdad y los mismos derechos a la verdad, la justicia y la reparación. Del mismo modo, a partir de la interpretación literal de la definición de víctima contenida en la Ley 1448, "se estarían excluyendo del ámbito de aplicación de la norma a las víctimas de graves violaciones de derechos humanos y de crímenes de lesa humanidad derivados de hechos de violencia socio política y ocurridos en el contexto del conflicto armado existente en el país pero sin relación causal con el mismo". Véase la Sentencia C-781/12 de la Corte Constitucional Colombiana, [en línea], disponible en $<$ http://ictj.org/ictj/docs/Ley1448/Sentencia_de_constitucionalidad-Ley1448C-781-12.pdf>.

12 Si bien la controversia es innata a cualquier corte para definir el universo de víctimas, no hay que desconocer la deuda histórica que se tiene con las víctimas "no reconocidas" de periodos que preceden a los dos cortes temporales que realiza la Ley 1448; en estos casos, haría falta al menos una reparación simbólica. 
Por otra parte, sobre el reconocimiento como víctimas para acceder a las reparaciones, en particular a la restitución de tierras, solo es necesario uno formal, "sin embargo, quienes huyeron de las zonas donde vivían pueden encontrar dificultades para que se las reconozca como víctimas, si no se les ha reconocido como personas desplazadas forzosamente" (AI, 2012: 6).

El tema central de la LVRT, como lo indica su nombre, es la tierra; no obstante, otro de los principales desafíos y cuestionamientos que esa Ley provoca es el "complejo proceso para identificar las tierras apropiadas indebidamente" (AI, 2012: 4). Al respecto, el Movimiento de Víctimas de Crímenes de Estado (MOVICE) ha señalado en comunicados dirigidos a la opinión pública que "el proceso de restitución de tierras enfrenta múltiples dificultades de orden político, fáctico, normativo e institucional, que de no ser superados no sólo impedirán la devolución de las tierras a las víctimas, sino que profundizará la violencia y revictimización de quienes solicitan al Estado la garantía y respeto de sus derechos a la verdad, la justicia, reparación integral y garantías de no repetición" (MOVICE, 2012a).

Si bien la restitución de tierras es el tema central, se ha señalado reiteradamente que la discusión también se amplía a la definición de la categoría de víctima; al respecto, organizaciones de víctimas y colectivos defensores de los derechos humanos han resaltado que no solo la categoría jurídica es excluyente - deja por fuera del universo de víctimas a varios grupos, por ejemplo, a las víctimas de crímenes de Estado-, sino que la delimitación temporal para acceder a los derechos allí consagrados es en extremo restrictiva y contradice el mismo reconocimiento que hace la Ley 1448 acerca de la existencia de un conflicto armado interno; reconocimiento que a su vez es problemático, ya que no incluye dentro de esta Ley a las víctimas de las bacrim, que son residuos del paramilitarismo; en otras palabras, la LVRT

agrava al dejar por fuera a las miles de familias que han sufrido por cuenta de las acciones del neo-paramilitarismo, eufemísticamente llamado bacrim. El reconocimiento formal de la existencia del conflicto armado es una cortina de humo que sirve para dejar sin derechos a las víctimas del conflicto socio político en todo el país al exigirles el tener que probar que el hecho fue cometido por un grupo armado y que guarde relación causal con el conflicto (Corporación Jurídica Libertad, 2011).

En esta dirección, asociaciones de víctimas resaltan lo siguiente:

No se ha tenido en cuenta la situación actual de las víctimas que estamos habitando dentro de los territorios o en espacios territoriales en los que constatamos la continuidad de la estrategia paramilitar con la participación directa, el apoyo 
y consentimiento de la fuerza pública. Las BACRIM son en nuestros territorios la prolongación del paramilitarismo como estrategia de guerra contra la población en la fase de control social territorial. Estamos experimentando nuevas fases de la guerra de guerrillas que en condiciones específicas han afectado a grupos de población civil. No hay derrota militar posible y los costos económicos, militares, humanos, ambientales son irreparables y son posibles de evitar muchos más. El conflicto armado político y social persiste y de esa constatación se quiere hacer caso omiso (Red de Alternativas a la Impunidad y a la Globalización del Mercado, 2011).

Ahora bien, la falta de participación de las víctimas en la propuesta de la Ley 1448 ha sido un factor que ellas han empleado para cuestionar la legitimidad de la misma, en especial respecto al alcance del derecho a la reparación: "Que el proceso de aprobación de la Ley 1448 de 2011 desconoció a las víctimas y sus propuestas, lo que la constituye en una ley inconsulta. Iniciativa en la cual no se reconoció como fundamento de la reparación a las víctimas, el deber de garantía, respeto y protección de los derechos humanos atribuible al Estado" (MOVICE, 2012b).

Según lo anterior, la LVRT es vista por colectivos de víctimas y organizaciones defensoras de derechos humanos como una imposición, que omitió las voces de los principales destinatarios y los puntos de vista de los partidos de oposición al gobierno del presidente Santos; lo cual, para dichos colectivos, fue intencionado, pues va de la mano de la falta de reconocimiento de la responsabilidad del Estado en el curso y prolongación del conflicto armado y, sobre todo, en muchos de los crímenes perpetrados en este marco, "[La Ley de Víctimas y Restitución de Tierras] fue aprobada sin consulta ni participación de los y las interesadas, en este caso las víctimas, y sin tener en consideración las propuestas de los partidos de oposición. [...] El contrato de transacción aprobado por el Senado es totalmente ilegal e inmoral, y busca evitar que se evidencie la responsabilidad del Estado en la mayoría de estos crímenes [...]" (Corporación Jurídica Libertad, 2011).

Esta exclusión en los canales de participación para la formulación y el debate del proyecto de la LVRT ha sido asumida por el MOVICE como una manifestación directa del gobierno para no reconocer a las víctimas de crímenes de Estado e incluirlas en el universo que señalan las Leyes 795 de 2005 y 1448 de 2011, "El MOvice no siente que la ley de víctimas reconozca a las víctimas de crímenes de Estado y, que habiendo entregado propuestas para que fueran tomadas en cuenta, incluso durante los debates del proyecto de ley, éstas no fueron reconocidas. Por lo tanto, partimos de la percepción que fuimos desconocidos e ignorados desde el inicio del proceso" (MOvice, 2012c). 
Del mismo modo, las críticas a la LVRT con frecuencia aluden a la falta de la aceptación de la responsabilidad del Estado en muchos de los crímenes cometidos en el contexto del conflicto armado interno en este marco jurídico: "Es tímido en reconocer la responsabilidad del Estado en la comisión de crímenes de lesa humanidad, infracciones al derecho humanitario y crímenes de guerra, es excluyente de víctimas de Estado, que fueron torturadas, desaparecidas, asesinadas en condiciones de indefensión cuando se trata de militantes disidentes" (Red de Alternativas..., 2011).

No obstante, el principal foco de descontento en relación con la LVRT aprobada es el universo de víctimas reconocidas para acceder a los derechos establecidos, en especial el derecho a la reparación y a la restitución de tierras:

La ley de víctimas excluye a las víctimas de crímenes perpetrados antes del 1 de enero de 1985, también deja por fuera a las víctimas de desplazamientos forzados masivos e individuales anteriores al ańo 1991, a las víctimas de desplazamiento forzado interurbano y a las víctimas de exilio. No reconoce a las víctimas de tortura, violencia sexual, tratos crueles e inhumanos, asesinatos y desaparición forzada cuando las víctimas pertenecen a grupos armados. Desconoce además a las víctimas de las llamadas "bacrim" por considerar que no se trata de grupos paramilitares (MOVICE, 2012d).

En esta dirección, para el MOVICE, la LVRT va en contravía del "principio de universalidad" y tiende a desconocer la historia sociopolítica del país, al dejar por fuera del cuerpo de la ley periodos históricos que se encuentran directamente inscritos en el largo conflicto armado interno. En otras palabras, la LVRT también va en contravía de la memoria histórica del país:

Nuestra memoria popular constata que el proyecto de ley parte de una mentira histórica [...] El proyecto de ley excluye la matanza de las bananeras, la persecución del gaitanismo, los crímenes del 14 de septiembre de 1977, los torturados y desaparecidos de los 70, las desapariciones y ejecuciones en la contra toma del palacio de Justicia en 1985. La ley de víctimas desconoce el derecho a la memoria y en este sentido no comprende un articulado específico sobre la memoria histórica, en el que se retomen los aportes de la Comisión Ética, y las construcciones que desde tiempo atrás se han venido desarrollando (Red de Alternativas..., 2011).

El hecho de haber definido la fecha de 1 de enero de 1986 y 1991 para el reconocimiento de la condición de víctimas y despojados respectivamente, resignifica la definición temporal de la violencia socio política en el país, negando crímenes tan graves como el genocidio político contra la Unión Patriótica y el 
Partido Comunista, la toma y la retoma del Palacio de Justicia y gran parte de las masacres que representan el periodo fundacional de la violencia paramilitar (MOVICE, 2012e).

Las citas anteriores dejan en claro que la LVRT en Colombia ha logrado articular demandas colectivas provenientes de las víctimas, pero no como una virtud propia, sino como un rechazo común manifestado públicamente. Del mismo modo, esa Ley no da cuenta de las dimensiones políticas asociadas tanto al problema de la restitución de tierras, como a su apropiación por parte de los actores armados ilegales, y en específico del paramilitarismo — cuestión señalada y denunciada por las mismas víctimas-. En este orden de ideas, si con la Ley de Justicia y Paz "la investigación judicial tiende, por tanto, a sobrevisivilizar $[$ sic $]$ los aspectos delincuenciales de la guerra y a invisibilizar sus aspectos políticos" (СмH, 2012: 20), con la LVRT ocurre una lógica similar: se establecen "las medidas de atención, asistencia y reparación integral a las víctimas" para hacer efectivo el goce de sus derechos, pero no se reconocen los problemas y las dificultades intrínsecas a la restitución de tierras cuando el conflicto armado interno sigue en curso.

\section{Consideraciones finales}

Se ha encontrado que la Ley de Víctimas y Restitución de Tierras ha provocado un rechazo generalizado entre las víctimas, visible en el llamado a la acción y a la movilización en contra de lo que allí se estipula en relación con el derecho a la reparación y, en específico, respecto a la restitución de tierras y la definición y delimitación del universo de víctimas amparadas en esta Ley. Es así como la LVRT ha sido tildada, por parte de asociaciones de víctimas afines al MOVICE, como un encubrimiento de la impunidad, motivo suficiente para rechazarla del todo,

También se propone articular al MOVICE a todas las víctimas que no son admitidas en esta ley para que por medio de las estrategias de lucha contra la impunidad del MOVICE se conviertan en un grupo de presión frente a las falencias de la ley. Para enfrentar estas cláusulas, el MOVICE implementará acciones judiciales acompañadas de acciones políticas que visibilicen las necesidades reales de las víctimas y las consecuencias de la aplicación de la ley (MOvice, 2012d).

Este rechazo a la LVRT por parte de las víctimas conduce a identificar su posicionamiento frente a la misma y así poder señalar que la consideran ilegítima 
por no verse reconocidas en ese cuerpo jurídico. La LVRT no representa los intereses de las víctimas, no las reconoce en su totalidad, las excluye y, por esta causa, reproduce las lógicas de exclusión presentes en la Ley 975 de 2005.

¿A qué ha conducido este rechazo de la LVRT? A la articulación de nuevas y viejas demandas, esta vez vinculadas al problema de la restitución de tierras. La expresión de la demanda mediante un rechazo abierto y público, y a través de distintas formas de movilización y protesta, y en especial el rechazo a una categoría jurídica que restringe aún más el universo de víctimas del conflicto armado colombiano, demuestran la importancia del acto de nombrar para la configuración de una identidad colectiva. Para esto último ha sido útil la LVRT, por este medio las víctimas han consolidado una identidad construida a partir de la referencia a una clasificación jurídica que las nombra, pero de la cual se busca una desclasificación a modo de acto de resistencia.

Esta clasificación explícita en la definición de víctima que se plantea en la Ley 1448 produce una desclasificación por parte de las víctimas que se orienta a resignificar el pasado, la historia reciente y la misma noción de víctima; estas resignificaciones son las que han provocado la resistencia frente a esa Ley.

Por otra parte, el posicionamiento de las víctimas respecto a la Ley 1448 de 2011 evidencia que existen "espacios en disputa", como la reparación, la memoria y la misma definición de víctima; espacios en donde las víctimas demandan al otro representado en el Estado, el reconocimiento de su responsabilidad en el surgimiento, prolongación y degradación del conflicto armado.

\section{Referencias}

Acevedo, Laura, 2012, "Reflexiones en torno a la categoría de víctima: una mirada a las organizaciones de víctimas de crímenes de Estado en Medellín”, ponencia presentada en Terceras Jornadas Debates Actuales de la Teoría Política Contemporánea 2012, [en línea], disponible en <http://www.academia.edu/1992644/Reflexiones_en_torno_a_la_categoria_de_ victima_Una_mirada_a_las_organizaciones_de_victimas_de_crimenes_de_Estado_en_ Medellin>, consultado el 15 de mayo de 2013.

Achugar, Hugo, 1992, "Historias paralelas, historias ejemplares: la historia y la voz del otro", Revista de Crítica Literaria Latinoamericana, núm. 36, pp. 51-73.

Amnistía Internacional (AI), 2012, Colombia: La Ley de Victimas y Restitución de Tierras, Madrid, Amnistía Internacional.

Blair, Elsa, 2008, “Los testimonios o las narrativas de las memorias”, Estudios Políticos, núm. 32 (enero-junio), pp. 85-115. 
Blair, Elsa, 2002, "Memoria y narrativa: la puesta de dolor en la escena pública”, Estudios Políticos, núm. 21 (julio-diciembre), pp. 9-28.

Blair, Elsa, et al., 2008, De memorias y de guerras. La Sierra, Villa Liliam y el 8 de marzo en Medellin. Informe final de investigación, Medellín, Alcaldía de Medellín/IDEA/Colciencias/ Universidad de Antioquia.

Booth, Katherine, 2007, Los derechos de las victimas ante la Corte Penal Internacional: Manual para las victimas, sus representantes legales y ONG, París, Federación Internacional de los Derechos Humanos.

Carrizosa, Catalina, 2010, "El trabajo de la memoria como vehículo de empoderamiento político: la experiencia del Salón del Nunca Más”, Boletín de Antropología, vol. 25, núm. 42, pp. 36-56.

Centro de Memoria Histórica (смн), 2012, Justicia y Paz: ¿Verdad judicial o verdad histórica?, Bogotá, Taurus.

Cepeda, Iván, y Claudia Girón, 2006, “Testigos históricos y sujetos de justicia”, en Camila De Gamboa (ed.), Justicia transicional: teoría y praxis, Bogotá, Universidad del Rosario.

Comisión Nacional de Reparación y Reconciliación (CNRR), 2009, Memorias en tiempos de guerra. Repertorio de iniciativas, Bogotá, Puntoaparte editores.

Corporación Jurídica Libertad, 2011, “No todo es bueno en la aprobada ley de víctimas”, 27 de mayo de 2011, [en línea], disponible en <http://www.movimientodevictimas.org/component/content/article/108-actividades/actividades/928-no-todo-es-bueno-en-la-aprobadaley-de-vctimas.html>, consultado el 10 de marzo de 2013.

Daza, Gisela, 2006, “Las víctimas en la socialización”, Nómadas, núm. 25 (octubre), pp. 110-117.

Delgado, Mariana, 2011, Las víctimas como sujetos politicos en el proceso de Justicia y Paz en Colombia: discursos imperantes y disruptivos en torno a la reconciliación, la verdad, la justicia y la reparación, tesis para obtener el grado de doctora en Ciencias Sociales con mención en Sociología de la Flacso México.

Dussel, Enrique, 1998, Arquitectónica de la ética de la liberación. Ética de la liberación ante Apel, Taylor y Vattimo, México, Universidad Autónoma del Estado de México.

García, Clara Inés, 2009, "Límites y posibilidades de construcción de ciudadanía en Colombia", Política y Cultura, núm. 32 (otoño), pp. 79-102.

García, María Inés, 2006, Espacio y poder: el espacio en la reflexión de Michael Foucault, México, UAM Xochimilco. 
Guerrero, Víctor, 2007, "La víctima de ocupante sin lugar a lugar sin ocupante", en Guillermo Hoyos (comp.), Las víctimas frente a la búsqueda de la verdad y reparación en Colombia, Bogotá, Pontificia Universidad Javeriana.

Ibarra, María Eugenia, 2011, "Mujeres, verdad, justicia y reparación en Colombia”, Universitas Humanística, núm. 72 (julio-diciembre), pp. 247-273.

Jelin, Elizabeth, 2002, Los trabajos de la memoria, Madrid, Siglo XXI editores.

Jimeno, Myriam, 2010, “Emociones y política. La 'víctima’ y la construcción de comunidades emocionales", [en línea], <disponible en http://www.scielo.br/scielo.php?pid=S010493132010000100005\&script=sci_arttext\&tlng=es. , consultado el 20 de marzo de 2013.

Kalmanovitz, Pablo, 2010, "Justicia correctiva vs. justicia social en casos de conflicto armado", Revista Estudios Socio-Jurídicos, vol. 12, núm. 2, pp. 59-85.

Lechner, Norbert, 1986, La conflictiva y nunca acabada construcción del orden deseado, Santiago de Chile, Flacso Chile.

Ley 1448 de 2011 (Ley de Víctimas y Restitución de Tierras), 2011, [en línea], disponible en <http://www.leydevictimas.gov.co/documents/10179/19132/completo.pdf>, consultado el 15 de agosto de 2012 .

Molina, Nelson, 2010, "Reconstrucción de memoria en historias de vida. Efectos políticos y terapéuticos”, Revista de Estudios Sociales, núm. 36, pp. 64-75.

MOvice, 2012a, "Carta al presidente Juan Manuel Santos previa movilización del 6 de marzo", 16 de julio de 2012, [en línea], disponible en <http:/www.movimientodevictimas.org/ versionantigua/index.php?option=com_content\&view=article\&id=1207: carta-del-moviceal-presidente-juan-manuel-santos-previa- movilizacion-del-6-de-marzo\&catid=50:6-demarzo\&Itemid=554 >, consultado el 10 de marzo de 2013.

MOvice, 2012b, "Declaración Pública Comité de Impulso Ampliado del Movice Nacional", 16 de julio de 2012, [en línea], disponible en <http://www.movimientodevictimas.org/ component/content/article/58-documentos-/conclusiones-encuentros/976-declaracionpublica-comite-de-impulso-ampliado-del-movice-nacional.html>, consultado el 10 de marzo de 2013.

MOVICE, 2012c, “Comunicado sobre la reglamentación de la ley de víctimas", 16 de julio de 2012, [en línea], disponible en <http:/www.movimientodevictimas.org/index.php?option=com_ content\&view=article\&id=1100: comunicado-sobre-regamentacion-de-ley-de-victimas\&ca tid=25:bogot\&Itemid=496> consultado el 10 de marzo de 2013.

Perfiles Latinoamericanos | vol. 23, núm. 46, julio-diciembre de 2015 | FLacso México

Mariana Delgado Barón | Las víctimas del conflicto armado colombiano en la Ley de Víctimas y Restitución de Tierras: apropiación y resignificación de una categoría jurídica | pp. 121-145 
MOVice, 2012d, "Los problemas de la ley de víctimas y restitución de tierras", agosto 15 de 2012, [en línea], disponible en $<\mathrm{http} / /$ www.conlospiesporlatierra.net/?p=1580>, consultado el 12 de marzo de 2013.

MOvice, 2012e, "El Movimiento Nacional de Víctimas advierte sobre inconstitucionalidad de la ley de víctimas", 16 de julio de 2012, [en línea], disponible en <http://www.movimientodevictimas.org/component/content/article/38-documentos-/documentos/849-el-movimiento-nacional-de-vctimas-advierte-sobre-inconstitucionalidad-de-la-ley-de-vctimas.html>, consultado el 12 de marzo de 2013.

Rancière, Jacques, 2006, Politica, policía, democracia, Santiago de Chile, Lom Ediciones.

Ravinovich, Silvana, 2003, “La mirada de las víctimas. Responsabilidad y libertad”, en José M. Reyes Mate (ed.), La ética ante las victimas, Barcelona, Anthropos.

Rebolledo, Olga, y Lina Rondón, 2010, "Reflexiones y aproximaciones al trabajo psicosocial con víctimas individuales y colectivas en el marco del proceso de reparación", Revista de Estudios Sociales, núm. 36 (agosto), pp. 40-50.

Red de Alternativas a la Impunidad y a la Globalización del Mercado, 2011, "Declaración ante la ley de Transición y debate de Víctimas: dignificación e imaginación”, 12 de marzo de 2011, [en línea], disponible en <http://justiciaypazcolombia.com/Declaracion-ante-la-ley-de>, consultado el 10 de marzo de 2013.

Retamozo, Martín, 2010, “Sujetos políticos: teoría y epistemología. Un diálogo entre la teoría del discurso, el (re)constructivismo y la filosofía de la liberación en perspectiva latinoamericana", Ciencia Ergo Sum, vol. 18, núm. 1, [en línea], disponible en <http://www.redalyc.org/ articulo.oa?id=10416528011>, consultado el 16 de julio de 2013.

Rodríguez, Eduardo, 2010, “¿s posible una sociología jurídica crítica? Elementos para una reflexión”, Opinión Jurídica, vol. 9, núm. 17, pp. 19-34.

Sánchez, Gonzalo, 2010, “Los victimarios ante los estrados judiciales. Notas de presentación del libro Testimonios perturbadores: ni verdad ni reconciliación en las confesiones de violencia de Estado. Uniandes-Ceso/Departamento de Ciencia Política/Fundación Ideas para la Paz, Bogotá, 2009. De: Leigh A. Payne”, Análisis Político, vol. 23, núm. 68 (enero-abril), pp. 129-133.

Sánchez, Gonzalo, 2008, “Tiempos de memorias, tiempos de víctimas”, Análisis Politico, núm. 63 (mayo-agosto), pp. 3-21.

Sánchez, Gonzalo, 2006, Guerras, memoria e historia, Medellín, La Carreta Histórica.

Scott, James, 2007, Los dominados y el arte de la resistencia, México, Ediciones Era. 
Villa, Juan David et al, 2007, Nombrar lo innombrable. Reconciliación desde la perspectiva de las víctimas, Bogotá, CINEP.

Wieviorka, Michael, 2009, Violence: A New Approach, Londres, SAGE.

Zemelman, Hugo, 1990, “Los sujetos sociales una propuesta de análisis”, Revista Acta Sociológica, vol. 3, núm. 2, pp. 89-104.

Recibido el 24 de julio de 2013. Aceptado el 27 de octubre de 2014. 